\title{
Endoscopic ultrasound-guided gastrojejunostomy using fully covered metal stent combined with large-loop double-pigtail stent for malignant afferent loop syndrome
}

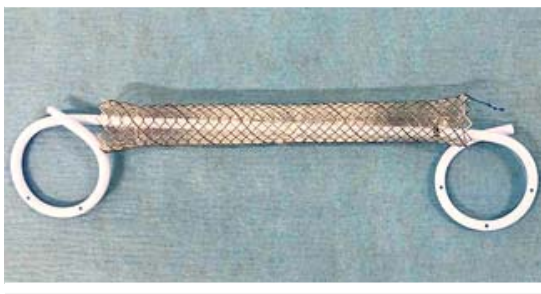

- Fig. 1 The modified stent system comprises a large-loop double-pigtail plastic stent within a fully covered self-expandable metal stent.

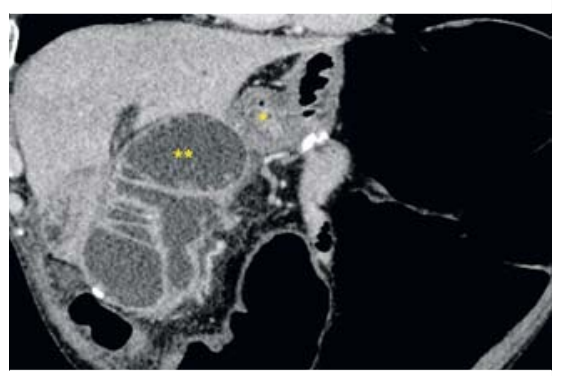

- Fig. 2 Contrast-enhanced computed tomography revealed a dilated afferent loop $\left({ }^{* *}\right)$ in close proximity to the stomach $\left({ }^{*}\right)$.

Afferent loop syndrome (ALS) is a known adverse event following Whipple procedure. A palliative surgical bypass is invasive and can only be performed in a limited selection of patients [1]. Recently, a minimally invasive approach, endoscopic ultrasound-guided gastrojejunostomy (EUS-GJ) using a lumen-apposing metal stent (LAMS), has been reported [2-4]. The LAMS has the advantages of preventing both stent migration and leakage of fluid. However, the LAMS is not available in many countries and is more expensive than the conventional fully covered selfexpandable metal stent (FCSEMS). Therefore, we developed a method involving an FCSEMS with antimigration properties, comprising a large-loop double-pigtail plastic stent within an FCSEMS ( $\triangleright$ Fig. 1). Herein, we describe technical tips for EUS-G] using the modified stent system ( Video 1).
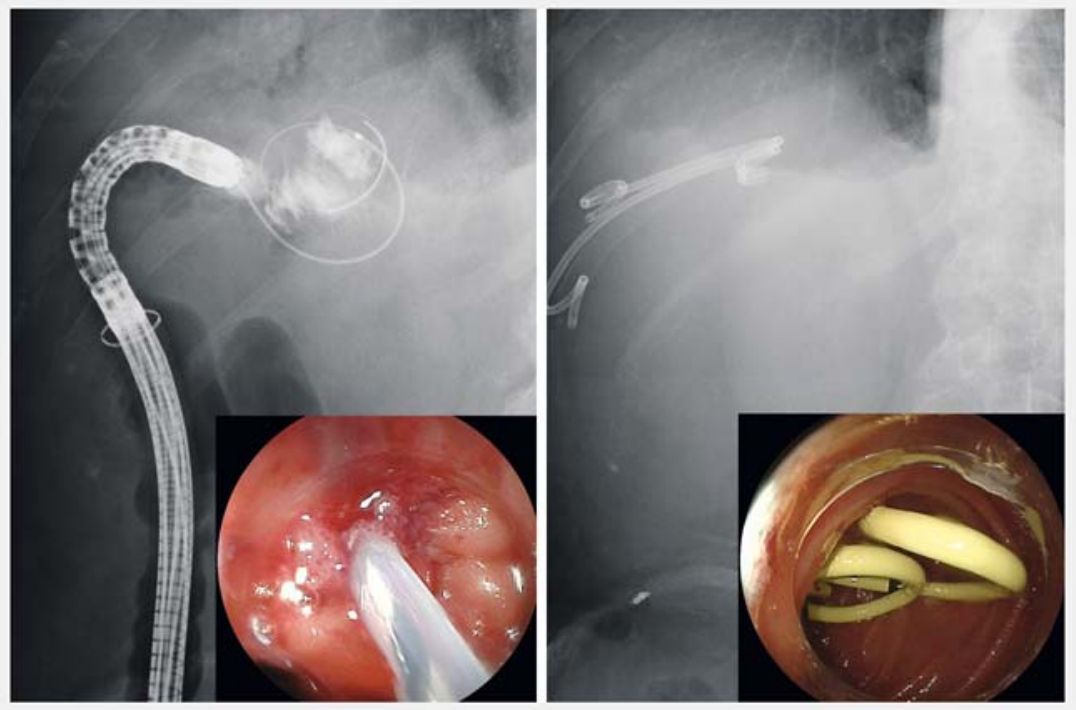

Fig. 3 Plastic stents were placed into the dilated afferent loop using balloon-assisted enteroscopy.

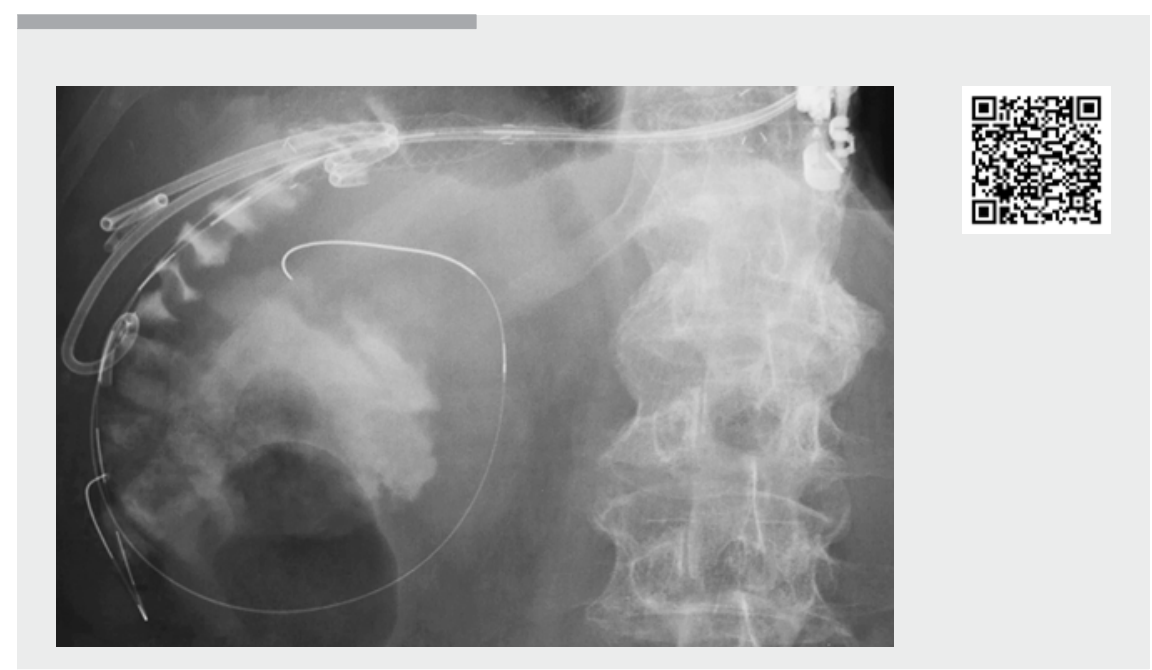

Video 1 Endoscopic ultrasound-guided gastrojejunostomy using a fully covered self-expandable metal stent combined with a large-loop double-pigtail plastic stent for successful treatment of afferent loop syndrome.

A 73-year-old man who had undergone a pancreaticoduodenostomy for pancreatic cancer presented with fever and abdominal pain. Computed tomography (CT) revealed ALS caused by local recur- rence of the cancer ( $\triangleright$ Fig. 2). Although plastic stents were placed into the dilated afferent loop using balloon assistedenteroscopy ( $\mathbf{F i g . 3}$ ), his clinical condition did not improve. 

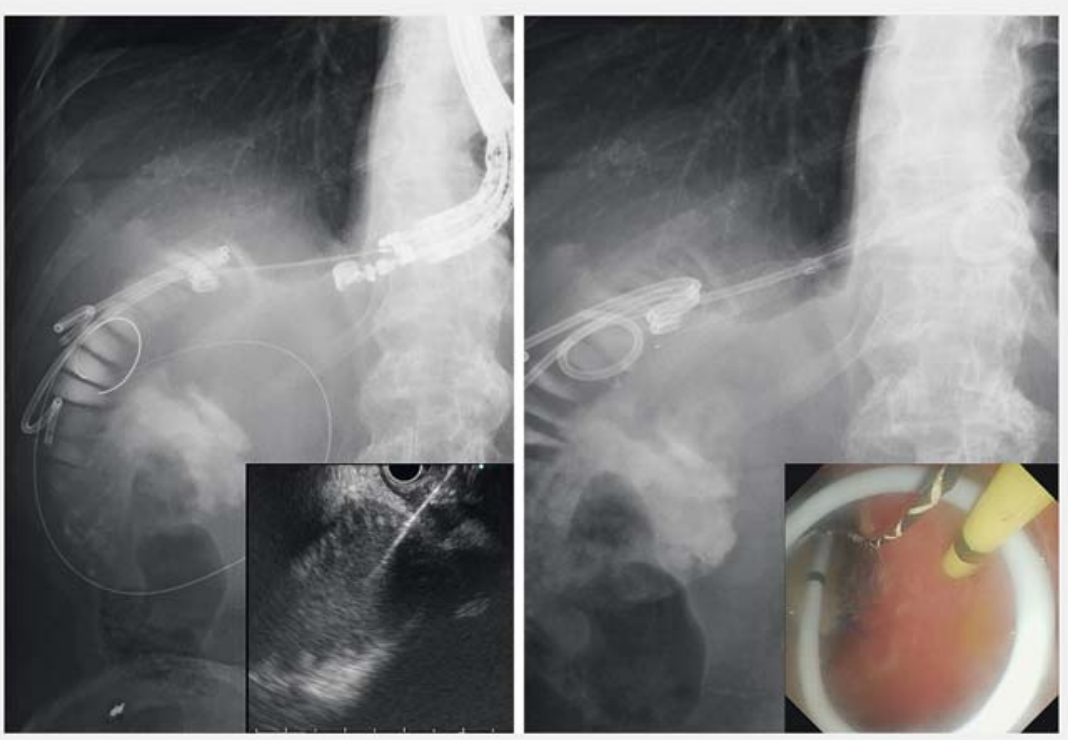

Corresponding author

\section{Hideyuki Shiomi, MD, PhD}

Division of Gastroenterology, Department of Internal Medicine, Kobe University Graduate School of Medicine, 7-5-1 Kusunoki-cho, Chuo-ku, Kobe, Hyogo 650-0017, Japan Fax: +81-78-3826309

hshiomi@med.kobe-u.ac.jp

\section{References}

[1] Pannala R, Brandabur JJ, Gan SI et al. Afferent limb syndrome and delayed $\mathrm{GI}$ problems after pancreaticoduodenectomy for pancreatic cancer: single-center, 14-year experience. Gastrointest Endosc 2011; 74: 295 302

[2] Ikeuchi N, Itoi T, Tsuchiya T et al. One-step EUS-guided gastrojejunostomy with use of lumen-apposing metal stent for afferent loop syndrome treatment. Gastrointest Endosc 2015; 82: 166

Endoscopic ultrasound-guided gastrojejunostomy was performed using a fully covered self-expandable metal stent combined with a large-loop double-pigtail plastic stent for afferent loop syndrome.

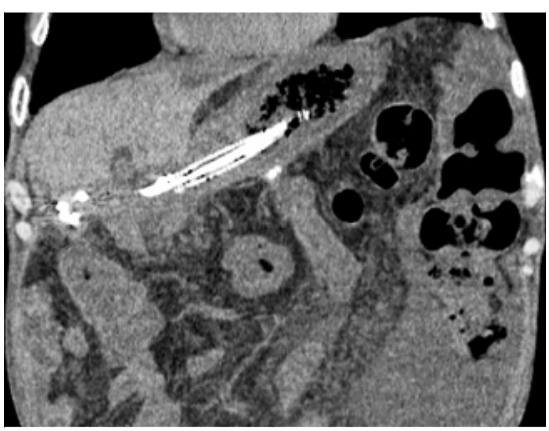

- Fig. 5 Computed tomography showed decompression of the afferent loop.

We attempted EUS-G]. The dilated afferent loop was punctured from the stomach with a 19-gauge fine-needle aspiration needle, through which a 0.025 -inch guidewire was inserted. A cautery dilator was used to make an incision into the needle tract and a 4-mm balloon catheter was used to dilate the tract. A $10 \mathrm{~mm} \times$ $8 \mathrm{~cm}$ FCSEMS (BONA stent; Standard SciTech Inc., Seoul, Korea) was deployed to appose the dilated afferent loop and the stomach. Finally, a $7 \mathrm{Fr} \times 8 \mathrm{~cm}$ large-loop double-pigtail plastic stent (Double Pigtail; Medi-Grobe GmbH, Germany) was placed through the FCSEMS ( $\triangleright$ Fig.4).
The patient's symptoms rapidly disappeared.

CT 10 days after the procedure showed improvement of the dilated afferent loop ( $\triangleright$ Fig. 5).

This modified stent system is helpful in preventing stent migration and leakage of fluid, similarly to LAMS. In addition, it has a lower cost compared with LAMS. The system may be a treatment option when performing EUS-G] for ALS.

Endoscopy_UCTN_Code_TTT_1AS_2AG

Competing interests

None

The authors

Hideyuki Shiomi ${ }^{1}$, Takashi Kobayashi ${ }^{1}$, Arata Sakai ${ }^{1}$, Yuuki Shiomi ${ }^{1}$, Atsuhiro Masuda', Edgardo M. Bondoc ${ }^{2}$, Yuzo Kodama ${ }^{1}$

1 Division of Gastroenterology, Department of Internal Medicine, Kobe University Graduate School of Medicine, Kobe, Japan

2 Institute of Digestive and Liver Disease, St. Luke's Medical Center, Quezon City, Philippines

\section{ENDOSCOPY E-VIDEOS}

https://eref.thieme.de/e-videos

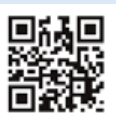

Endoscopy E-Videos is a free access online section, reporting on interesting cases and new techniques in gastroenterological endoscopy. All papers include a high quality video and all contributions are freely accessible online.

This section has its own submission website at

https://mc.manuscriptcentral.com/e-videos 